\title{
Results of a randomised trial of treating abnormal hypermetropia from the age of 6 months
}

\author{
R M Ingram, P E Arnold, S Dally, J Lucas
}

\begin{abstract}
Children who were abnormally hypermetropic at the age of 6 months were randomly allocated treatment with spectacles or no treatment. The eventual incidence of squint was the same in both groups (approximately $24 \%$ ). The last known visual acuity of the two groups was not significantly different either. Therefore there is no indication to screen infants with a view to preventing squint/amblyopia by optical correction of hypermetropia. If, however, the children allocated treatment are divided into two subgroups - those who wore glasses consistently and those who probably or certainly did not do so - the incidence of squint was the same, but the last known acuities of those who consistently wore glasses may be better than those who did not do so. This suggests that it may yet prove possible to prevent severe amblyopia.
\end{abstract}

A previous paper ${ }^{1}$ described an attempt to prevent squint and/or amblyopia by spectacle correction of abnormal hypermetropia from the age of 1 year. In the event the attempt proved unsuccessful. A possible explanation for this lack of success could be that treatment was started too late. This is a report of a similar randomised trial of treatment started at the age of 6 months.

\section{Patients and methods}

\section{PATIENTS}

Children living within the boundaries of the Kettering and District Health Authority and those living in Market Harborough were refracted at the age of 6 months. Those who had +4.00 or more D hypermetropia in any one or more meridia of either eye entered this trial. This level of hypermetropia was chosen after a preliminary, unpublished, study of the range of refractions at 6 months had shown that approximately $9 \%$ of children have this amount of hypermetropia and that such children had a $20 \%$ chance of having some visual defect. The question of informed consent proved difficult, because many mothers could not appreciate the issues involved in their child being identified as being at risk for squint and/or amblyopia. They were therefore told their child was included in a long-term study of the possibility of preventing squint and amblyopia, but the exact details of the randomisation techniques were not explained unless requested.

Three hundred and seventy two children born between July 1978 and July 1981 entered the trial. One child was excluded because he had congenital nystagmus.
PROTOCOL AND METHODS

All refractions were performed by the same person (RMI) at 1 metre after cycloplegia with cyclopentolate $1 \%$ instilled twice (40 minutes and 30 minutes) before retinoscopy. In order to categorise the children into their various degrees of hypermetropia a figure was derived which is recorded as the 'refraction' for each child. This figure was obtained by subtracting $1.75 \mathrm{D}$ from the 1 metre retinoscopy figure in the most hypermetropic meridian. This figure is distinct from the prescription (if given), which was based on subtracting 2.00 D from each meridian of the retinoscopy. Thus, for a child with a retinoscopy of $+4 \cdot 00 /+6 \cdot 00$ the 'refraction' would be $+4 \cdot 25$ $\mathrm{D}$, but the prescription would be $+2.00 \mathrm{DS} /$ $+2.00 \mathrm{D}$ cyl axis $90^{\circ}$. Half of the children who had +4.00 or more $D$ meridional hypermetropia were randomly allocated treatment with spectacles. Refraction was repeated at 1 and $31 / 2$ years, and in between if the clinical situation necessitated it - for example, if squint became manifest or if the glasses needed replacing. Observation was continued until the refraction became $<+2.00 \mathrm{DS}$ right and left and $<+1.50$ $\mathrm{D}$ astigmatism. If squint was detected, the child was treated on conventional lines, that is, spectacles, occlusion, operation as necessary.

An attempt was made to see the children every three months, but, as in the previous trial, attendance was irregular in some cases and reminders were sent when necessary. Fifty six children dropped out at an early stage and others as time progressed. All were recalled for assessment at age $31 / 2$.

In assessing the results we considered only two matters. The first was the presence or absence of squint as demonstrated by the cover test, and the second was the last known corrected visual acuity with spectacles if worn. Visual acuity was recorded on either the linear Sheridan-Gardiner or Snellen tests.

\section{COMPLIANCE WITH TREATMENT}

An assessment of whether glasses were being worn was attempted and recorded each time a child attended. Some children obviously wore the glasses consistently, but it was apparent that some wore them irregularly and others not at all. The 'treated' children were therefore divided into two groups: $\mathrm{T}+$ where compliance was judged (by inspection of the records) to be satisfactory and $T \pm$ where it was judged to be unsatisfactory. This allocation was made before the analysis of the visual results.

Results

Information about the presence of squint
Correspondence to: $\operatorname{Dr} \mathbf{R} M$ Ingram, Kettering Distric Road, Kettering, Northants NN16 8UZ.

Accepted for publication 28 September 1989 
TABLE I Incidence of squint

\begin{tabular}{lllll}
\hline & & No squint & Squint & $\%$ Squint \\
\hline No treatment & & 104 & 37 & 26 \\
Treatment & $\mathrm{T}+$ & 53 & 17 & 24 \\
& $\mathrm{~T} \pm$ & 57 & 17 & 23 \\
\hline
\end{tabular}

TABLE II Final visual acuity

\begin{tabular}{llllllll}
\hline & $6 / 6$ & $6 / 9$ & $6 / 12$ & $6 / 18$ & $6 / 24$ & $6 / 36$ & $6 / 60$ \\
\hline No treatment & 54 & 58 & 11 & 8 & 6 & 2 & 2 \\
Treatment & 72 & 44 & 17 & 4 & 2 & 2 & 3 \\
\hline
\end{tabular}

TABLE III Final visual acuity

\begin{tabular}{lcccccccc}
\hline & & $6 / 6$ & $6 / 9$ & $6 / 12$ & $6 / 18$ & $6 / 24$ & $6 / 36$ & $6 / 60$ \\
\hline No treatment & & 54 & 58 & 11 & 8 & 6 & 2 & 2 \\
Treatment & $\mathrm{T}+$ & 37 & 25 & 6 & 1 & 0 & 0 & 1 \\
& $\mathrm{~T} \pm$ & 35 & 19 & 11 & 3 & 2 & 2 & 2 \\
\hline
\end{tabular}

TABLE IV Final visual acuity and treatment

\begin{tabular}{lcc}
\hline & $6 / 12$ or better & $6 / 18$ orworse \\
\hline Treatment $T+$ & 68 & 2 \\
No treatment & 123 & 18 \\
\hline
\end{tabular}

$\chi^{2}=4 \cdot 26, \mathrm{df}=1, \mathrm{p}<0.05$.

detected by the cover test, corrected visual acuity of the 'worse' eye after all additional treatment including occlusion, compliance with the initial treatment, and the cycloplegic refraction at age $31 / 2$ is available for 285 of the 372 children who originally entered the trial. This forms the basis of the results shown above. Three of the children recorded as having squint had divergent squint and the remaining 68 had convergent squint.

Even if the children drawn for treatment are split into two subgroups according to their compliance with treatment ( $T+$ and $T \pm$ ), it is clear that treatment from the age of 6 months has not altered the incidence of squint at all (Table I).

The last known acuities of the 'worse' eye of the children divided into two groups - that is, those drawn for treatment and those drawn for no treatment - are shown in Table II. A statistically significant difference cannot be identified.

If the children drawn for treatment are divided into two subgroups according to their compliance with treatment ( $T+$ and $T \pm$ ), the figures in Table II become those shown in Table III.
A statistically significant difference can now be identified if the $T+$ group are compared with those drawn for no treatment (Table IV).

\section{Discussion}

Abnormal hypermetropia is clearly associated with squint and amblyopia which does not respond to current methods of treatment. ${ }^{2}$ In this study the prescription of spectacles from the age of 6 months did not reduce the incidence of squint (Table I), nor did it lead to a significantly improved final visual acuity after all additional treatment had been given (Table II). At present, therefore, there is no indication to screen children at the age of 6 months with a view to prescribing spectacles for those who are abnormally hypermetropic in the hope that this will reduce the incidence of squint or reduce the severity of amblyopia.

However, those children who wore their glasses consistently may have achieved a better final visual acuity than those who did not wear glasses (Table III). The evidence for this is not impressive: a significant difference depends on how the figures are arranged for statistical analysis (see Table IV). These results do no more than suggest that further research into the prevention of amblyopia, as distinct from squint, may yet prove worthwhile.

An incidental observation on this sample of children was that those whose initial hypermetropia became less by the age of $31 / 2$ had a significantly lower incidence of squint and a better last known visual acuity than those whose hypermetropia did not become reduced. This association between emmetropisation ${ }^{34}$ and the visual outcome is to be explored in more detail in another paper.

We thank Mrs L Neale for many hours of secretarial and administrative work.

1 Ingram RM, Walker C, Wilson JM, Arnold PE, Lucas J, Dally $S$. A first attempt to prevent amblyopia and squint by spectacle correction of abnormal refractions from age 1 year. Brf Ophthalmol 1985; 69: 851-3.

2 Ingram RM, Walker C, Wilson JM, Arnold PE, Dally S. Prediction of amblyopia and squint by means of refraction at age 1 year. Br $\mathcal{F}$ Ophthalmol 1986; 70: 12-5.

3 Fabian G. Ophthalmological serial examination of 1200 children in their second year of life. Acta Ophthalmol (Kbh) 1966; 44: 473-9.

4 Ingram RM, Barr A. Changes in refraction between the ages of 1 and 31/2 years. Br f Ophthalmol 1979; 63: 339-42. 